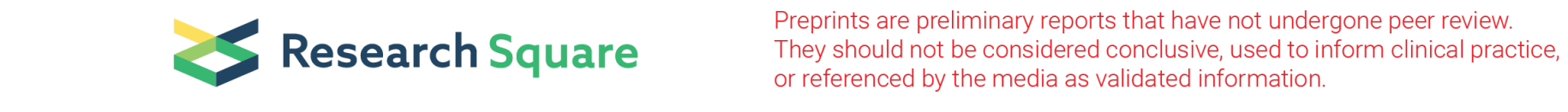

\title{
Prevalence of Depression among HIV-Positive Adults on Antiretroviral Therapy in O.R. Tambo, Eastern Cape, South Africa: A cross-sectional descriptive study
}

\author{
Dlulane Yola Zimasa \\ Walter Sisulu University \\ Apalata Teke \\ Walter Sisulu University \\ Dominic Targema Abaver ( $\nabla$ dominicabaver@yahoo.com ) \\ https://orcid.org/0000-0002-7749-9167
}

\section{Research article}

Keywords: Depression, HIV Positive Adults, Anti-Retroviral Therapy, O.R. Tambo

Posted Date: December 4th, 2020

DOI: https://doi.org/10.21203/rs.3.rs-33145/v2

License: (c) (i) This work is licensed under a Creative Commons Attribution 4.0 International License. Read Full License 


\section{Abstract}

Background Living with HIV/AIDS is associated with negative emotional and bodily symptoms; however, there is paucity of data on the prevalence and associated factors depression among this population. This study investigate the prevalence and factors contributing to depression among HIV-positive adults on antiretroviral therapy (ART) in O.R. Tambo Eastern Cape, South Africa.

Method This cross-sectional descriptive study involved 334 adults receiving ART in the two Community Health Centers in OR Tambo District, Eastern Cape, South Africa. The Beck's Depression Inventory (BDI-II) was used to collect data, in addition to a semi-structured questionnaire on coping mechanism and challenges in seeking help with depressive symptoms. Multiple logistic regression analysis were used to assess the factors associated with depression among the HIV-positive adults.

Results The prevalence of depression among the HIV-positive adults receiving ART was $44 \%$, and the majority of the patient's depression fall within the borderline and moderate threshold. The prevalence of depression was significantly higher among females $(71.0 \% ; p<0.0003)$ and unemployed $(73.0 \% ; p<0.0014)$ HIV-positive adults. Participants not benefiting from any form of social grant exhibited higher prevalence of depression $(79 \%)$. Race $(p=0.590)$, age $(p=0.338)$ and married participants $(p=0.511)$ show no statistical significant association between HIV-positive adults accessing ART and depression. Unadjusted logistic regression model show being female ( $\mathrm{OR}=1.99,95 \% \mathrm{Cl}: 1.23-3.23 ; \mathrm{p}<0.003)$ and unemployed $(\mathrm{OR}=1.73,95 \% \mathrm{Cl}$ : 1.08-2.77; $\mathrm{p}<0.014)$ were significantly associated with a likelihood of depression. Majority of the participants who could express their feelings of HIV disease and challenges in accessing ART felt more depressed (85\%) compared to those who could not express their feelings.

Conclusion The rate of depression among HIV/AIDS patients receiving ART is high. Early detection of depression and the challenges associated with accessing treatment and treating would help in improving the compliance to treatment as well as quality of life.

\section{Background}

Human Immunodeficiency Virus (HIV) and Acquired Immune Deficiency Syndrome (AIDS) some of the most overwhelming illnesses in the history of mankind. Global HIV statistics shows that out of 37.9 million [32.7 million-44.0 million] people were living with HIV (end of 2018), 24.5 million [21.6 million-25.5 million] people were accessing antiretroviral therapy at the end of June 2019. About 1.7 million [1.4 million-2.3 million] people became newly infected with HIV (end of 2018), 770000 [570 000-1.1 million] people died from AIDS-related illnesses same year ${ }^{1}$.

It is no longer news that South Africa is one of the countries with highest number of people living with HIV globally. According to Department of Statistics South Africa ${ }^{2}$, the estimated overall HIV prevalence rate is approximately $13.50 \%$ among the South African population. The total number of people living with HIV (PLWHIV) is estimated at approximately 7. 97 million in 2019. For adults aged $15-49$ years, an estimated $19.07 \%$ of the population is HIV positive. The disease, like any other chronic illness, can have an effect not only on the immune system of the body but also on the psychiatry state of the infected individual.

Epidemiological analysis of reported HIV/AIDS cases reveals that HIV/AIDS is affecting mainly young people in the sexually active age group (18 to 30 years). Women are disproportionately affected by HIV in South Africa. In 2017, 26\% of women were estimated to be living with HIV, compared to around $15 \%$ of men $^{3}$. In 2018, 140,000 women and 86,000 men became HIV positive. In the same year, 4.7 million women were living with HIV compared to 2.8 million men ${ }^{4}$. Poverty, the low status of women and gender-based violence have all been cited as reasons for this disparity in HIV prevalence 5 . The HIV prevalence among young women is nearly four times greater than that of young men ${ }^{6}$. 
In most developing countries, stigmatization of people who have terminal illnesses associated with social behaviors viewed by the society as negative, does not only push the patients to being reclusive, but denied them the urge to seek necessary required medical attention; in some extreme cases, depression. Stigmatized people often show psychiatric symptoms ${ }^{7}, a^{2}$ situation which leads to the definition of depression in some cases to be misinterpreted, even among clinicians, especially when symptoms and diagnosis are considered. This leads to a confounding confusion that often results to patients and family members portraying different things when they use the word depression, and some clinicians do find themselves using the same word but lack a common understanding.

According to Alan and Heather ${ }^{7}$, depression is considered a pathological and pervasive state of mood, where a depressed individual sees everything-self, world, and future-through a dark prism. These pathological signs include feelings of helplessness, hopelessness, and worthlessness, among many. However, depression is not sadness, given that patients who recover from depression often report being relieved to feel normal sadness again, though some of the depressive symptoms include persistent sad, anxious, or "empty" mood".

Depression is associated with both genetic (scientific) and negative life experiences (social). The two factors play parts in an individual's vulnerability to become depressed. This study however, considered HIV as some social aspects of etiology of depression. Stigmatization, arising from HIV, constitutes part of negative life experiences which may leave traces on the brain that adversely affect future responses to life circumstances and the probability of developing anxiety and depression. However, HIV infection itself does not cause depression, nor does the progression of the disease automatically lead to depression. Critical "crisis points" are common "entry" points of a depressive state in HIV-infected individuals. These crisis points include but not limited to level of tolerance to discrimination, abuse and difficulties in accessing HIV-related therapy such as easy access to ARVs, among many.

Depression is a mental disorder that is pervasive in the world affecting everybody irrespective of gender, race or age. It does not only pose a substantial public health challenge at social and economic level, but is also a significant contributor to global burden of disease affecting all communities across the world ${ }^{8}$. The correlation of HIV and depression is viewed from the perspective that, HIV disease, like any other chronic illness, can have an effect not only in the body but also in the mind. A number of reasons are cited for the presence of psychiatric disorders among people with HIV. The HIV infection enforces a considerable psychological burden with depression seen as the most common psychiatric disorder among HIV-positive adults $^{8}$. In fact, the combined effects of the virus on the central nervous system, the psychological impact of living with HIV, side effects of medication ${ }^{9}$ and results of social stigma and discrimination constitute some of the reasons for the high level of mental disorders affecting people living with HIV. In addition, economic cost of treating the HIV disease and the difficulties in accessing ART can trigger depression in HIV population. Two decades ago, $\mathrm{WHO}^{10}$ findings show that mental health disorders are common and affect one in four individuals (24\%) at some time in their life, though prevalence may vary from country to country with the overall prevalence of depression at approximately $10 \%$. In Africa, prevalence rates of major depressive disorder ${ }^{11}$ ranges from $3 \%$ to $54 \%$, meanwhile the prevalence of depression in HIV-positive individuals in South Africa ${ }^{12}$ range from $5 \%$ to $20 \%$. Among South Africans living in rural communities, the prevalence of mental disorders is reported to be $23.90 \%$, and $4.80 \%$, and depression is one of the major disorders ${ }^{13}$. Moosa and Jeenah ${ }^{14}$ have reported a high prevalence of comorbid depression among HIV positive individuals. The HIV-infected South African population could then be in danger of added burden of mental disorders in their lives.

Depressed persons with HIV frequently become non-adherent with their treatment, which may lead to higher HIV viral loads, higher infectiousness and poorer clinical outcomes ${ }^{15}$. When depressed, a patient exhibits symptoms associated with risky behavior, non-adherence to medications and shortened survival ${ }^{16}$. Failure to recognize depression may endanger both the patient and others in the community.

Despite the huge impact of HIV/AIDS on public health, there is limited information about the prevalence of depression among HIV-patients on ART and the factors associated with depression. Therefore, this study was conducted to establish the 
prevalence of depression and associated factors such as demographics, difficulties in accessing ARV, economic cost of treating HIV and alexithymia among HIV patients receiving ART in the rural communities of O.R. Tambo municipality of Eastern Cape, South Africa.

\section{Methods}

This cross sectional study was conducted at Community Health Care Centers of Port St Johns (PSJ CHC) and Makhotyana (MCHC), both in OR Tambo municipality of Eastern Cape, South Africa. The study was conducted on patients under HIV care at the ART venters of Port St Johns and Makhotyana, OR Tambo municipality, Eastern Cape. Three hundred and thirty four patients (200 from PSJ CHC and 134 from MCHC) of age 18 $\geq 50$ years that met the selection criteria were enrolled for the study.

The study was approved by the Ethical Committee of Walter Sisulu University (protocol number 050/2017). Permission from the Eastern Cape Department of Health was granted to conduct the research in the two Community Health Centers. The purpose of the study was explained to the participants after which they were requested to sign informed consent forms before the questionnaire was administered. Each patient was assured of confidentiality, and that his or her replies would not jeopardize benefits and privileges being enjoyed, neither would it, in a way prejudice the treatment given. Inclusion criteria include HIV-positive adults receiving ART care, while patients with known history of psychiatric illness, who were bereaved recently, female patient in post-partum period and patient not on ART were not included.

Instrumentation of data collection was structured questionnaire with interviews where necessary. The questionnaire contained measurable factors such as demographics and challenges in accessing ARVs as well as alexithymia. To ensure reliability, the questionnaire was translated from English to isiXhosa. A pilot study was conducted on 20 participants in Nyandeni Makhotyana CHC using the XBDI-II. This enabled the necessary adjustments to the questionnaire. In order to minimize selection bias, simple random sampling was done; where each individual was chosen entirely by chance and each member of the population had an equal chance, or probability, of being selected. Data was collected using the structured questionnaires and interviews. Contents of data instruments were taken from the Beck's Depression Inventory revised tool (BDI-II) and the Xhosa version of the BDI-II as translated by Steele and Edwards ${ }^{18}$. The prevalence of depression was assessed using Beck's Depression Inventory Scale which constitutes a total score of 63 . The cut off scores in BDI-11 and the South African version, the XBDI-11 are the same. A score of 0-9 is considered normal (not depressed) or absence of depression. The scores above 9 were considered to be depressed or to have presence of depression. Participants were required to select one option that best fits the way that he or she felt in the past two weeks. The scale permits selections of four responses given a weight of 0-3 with numerical values of 0 (low) to 3 (high) to indicate the degree of severity. In some categories, two alternative statements $(2 a$ and $2 b)$ are preserve at a given level ${ }^{19}$. These are then scored with a maximum total of 63 .

\section{Data analysis}

Descriptive statistics of frequency and percentages was used. Logistic regression analysis was applied to examine factors affecting HIV patients on ART. To estimate the chance of having depression, the odds ratio (OR) and corresponding confidence interval $(\mathrm{Cl})$ of $95 \%$ was calculated. A p-value less than 0.05 was considered statistically significant. All analyses were conducted with the Statistical Packages for Social Sciences, version 24.0 (SPSS, Chicago, IL, USA).

In terms of statistical significance, the value was set at a $95 \%$ confidence interval level $(p<0.05)$.

\section{Results}

The overall prevalence of depression (44\%) is shown in figure 1, while characteristics of study population is shown in table 1. Majority of the participants were Africans (99.1\%), unemployed (66.8\%), single (49.7\%) and were females (68.9\%). Most of 
the participants were in the age category of 30-39 (27\%).

Table 1: Socio-demographic characteristics of participants

\begin{tabular}{|c|c|c|}
\hline Variables & Frequency & Percentage \\
\hline \multicolumn{3}{|l|}{ Gender } \\
\hline Male & 10 & $31.1 \%$ \\
\hline Female & 230 & $68.9 \%$ \\
\hline \multicolumn{3}{|l|}{ Race } \\
\hline African & 331 & $99 \%$ \\
\hline Coloured & 03 & $1 \%$ \\
\hline White & - & - \\
\hline Indian & - & - \\
\hline \multicolumn{3}{|l|}{ Marital status } \\
\hline Single & 166 & $49.7 \%$ \\
\hline Married & 124 & $37.1 \%$ \\
\hline Divorced & 9 & $2.7 \%$ \\
\hline Widowed & 35 & $10.5 \%$ \\
\hline \multicolumn{3}{|l|}{ Age (years) } \\
\hline $18-19$ & 12 & $3.6 \%$ \\
\hline $20-29$ & 62 & $18.6 \%$ \\
\hline $30-39$ & 91 & 27.2 \\
\hline $40-49$ & 83 & $24.9 \%$ \\
\hline$>50$ & 86 & $25.7 \%$ \\
\hline \multicolumn{3}{|l|}{ Employment Status } \\
\hline Employed & 111 & $33.2 \%$ \\
\hline Unemployed & 223 & $66.8 \%$ \\
\hline \multicolumn{3}{|c|}{ Receiving social grant } \\
\hline Yes & 65 & $19.5 \%$ \\
\hline No & 269 & $80.5 \%$ \\
\hline
\end{tabular}

Table 2 shows the demographic factors associated with depression. Out of 334 participants, 147 (44\%) were confirmed depressed (Figure 1), with varying degrees of depression.

The prevalence of depression was significantly higher among females $(71.0 \% ; p<0.0003)$ and unemployed $(73.0 \% ; p<$ $0.0014)$ HIV-positive patients. With reference to social grant, participants not benefiting from any form of social grant exhibited higher prevalence of depression (79\%) compared to those on social grants $(21 \%)$. Race $(p=0.590)$, age $(p=0.338)$ and married participants $(p=0.511)$ show no statistical significant association between HIV and depression. We used unadjusted logistic regression models to examine factors related to depression (Table 2). In the model, being female (OR = $1.99,95 \% \mathrm{Cl}: 1.23-3.23 ; \mathrm{p}<0.003)$, unemployed ( $\mathrm{OR}=1.73,95 \% \mathrm{Cl}: 1.08-2.77 ; \mathrm{p}<0.014)$ were significantly associated with a likelihood of depression.

Table 2: Demographic factors and depression 


\begin{tabular}{|c|c|c|c|c|c|}
\hline \multicolumn{2}{|l|}{ ors } & \multirow{2}{*}{$\begin{array}{ll}\begin{array}{l}\text { Presence } \\
\text { depression }\end{array} & \text { of } \\
34(23 \%) & \end{array}$} & \multirow{2}{*}{$\begin{array}{ll}\begin{array}{l}\text { Absence } \\
\text { depression }\end{array} & \text { of } \\
70(37 \%) & \end{array}$} & \multirow{3}{*}{$\begin{array}{l}\begin{array}{l}\text { P- } \\
\text { value }\end{array} \\
0.003\end{array}$} & \multirow{2}{*}{$\begin{array}{l}\text { OR (95\% CI) } \\
1.99(1.23-3.23) \\
\end{array}$} \\
\hline$\overline{\operatorname{der}}$ & Male & & & & \\
\hline & Female & $113(77 \%)$ & $117(63 \%)$ & & \\
\hline \multirow[t]{2}{*}{3} & African & $146(44 \%)$ & $185(55 \%)$ & \multirow[t]{2}{*}{0.590} & \multirow{2}{*}{$\begin{array}{ll}0.634 & (0.057- \\
7.056) & \end{array}$} \\
\hline & Coloured & $1(n<5)$ & $2(n<5)$ & & \\
\hline \multirow[t]{5}{*}{$\overline{\text { groups }}$} & $18-19$ & $5(3 \%)$ & $7(4 \%)$ & \multirow[t]{5}{*}{0.338} & \multirow[t]{5}{*}{-} \\
\hline & $20-29$ & $29(20 \%)$ & $33(18 \%)$ & & \\
\hline & $30-39$ & $37(25 \%)$ & 54 (29\%) & & \\
\hline & $40-49$ & $31(21 \%)$ & $52(28 \%)$ & & \\
\hline & $>50$ & $45(31 \%)$ & $41(22 \%)$ & & \\
\hline \multirow[t]{4}{*}{ ital Status } & Single & $71(48 \%)$ & $95(51 \%)$ & \multirow[t]{4}{*}{0.511} & \multirow[t]{4}{*}{-} \\
\hline & Married & $52(35 \%)$ & $72(39 \%)$ & & \\
\hline & Divorced & $5(3 \%)$ & $4(n<5)$ & & \\
\hline & Widowed & $19(13 \%)$ & $16(9 \%)$ & & \\
\hline \multirow[t]{2}{*}{$\begin{array}{l}\text { loyment } \\
\text { is }\end{array}$} & Employed & $39(27 \%)$ & $72(38 \%)$ & \multirow[t]{2}{*}{0.014} & \multirow[t]{2}{*}{$\begin{array}{l}1.734 \\
2.774)\end{array}$} \\
\hline & Unemployed & $108(73 \%)$ & $115(62 \%)$ & & \\
\hline \multirow[t]{2}{*}{ jiving grant } & Yes & $31(21 \%)$ & $34(18 \%)$ & \multirow[t]{2}{*}{0.298} & \multirow{2}{*}{$\begin{array}{l}0.832 \\
1.432)\end{array}$} \\
\hline & No & $116(79 \%)$ & $153(82 \%)$ & & \\
\hline
\end{tabular}

Majority of the participants who could express their feelings (measured by means of alexithymia) of HIV disease and challenges in accessing ART felt more depressed (85\%) compared to those who could not express their feelings.

\section{Discussion}

The overall prevalence of depression in this present study was $44 \%$. This rate of depression falls within the lifetime prevalence of depressive disorders range between 22 to $61 \%$ in HIV-positive populations ${ }^{20}$. The finding of this study is in comparison with the findings of $\mathrm{WHO}^{21}$ especially in the area of mental health disorders, which occur in all regions and cultures of the world.

The findings of this study suggest that age of participants, marital status, race and receiving grant are not associated with development of depression as these variables were not statistically significant. However, gender and unemployment were significantly associated with depression among the participants. The gendered dimension of the prevalence of depression in this present study is in comparison with Nogueira et al. who reported an increased prevalence of depression among females $^{22}$. These rates however, differ from the findings of Bhatia and Munjal ${ }^{20}$ who did not find any significant difference in depression according to gender. The high rate of depression (77\%) seen in females could be associated with several factors, among which are myriad burdens in everyday life as a result of their social status and roles relative to men, which predisposes them to depression ${ }^{23}$.

The fear and lack of trust of participants in this study to express their feelings could be due to stigma which can limit the ability to access diagnostic and treatment services. Apparently, stigma seemed to be common; and internalized AIDS stigmas were prevalent among people living with HIV/AIDS ${ }^{24}$. Similarly, UNAIDS ${ }^{25}$ reports that the stigma attached to HIV 
and the discrimination against the infected and their families, coupled with the psychological relation, often becomes more complex and difficult to deal with compared to other illnesses. Comparatively, there were more participants who experienced difficulties in expressing their feelings (85\%) as against the few who could easily express their feelings (15\%) of depression, as seen from the findings of this study. The underlying factors are not unconnected with social forces which create overlapping and reinforcing stigmatized conditions that predispose individuals to HIV infections with limited ability to access diagnostic and treatment services that eventually affect the uptake of critical services such as ART, even with improved access.

Our study sought to establish prevalence of depression and associated factors that elucidate depression among HIV infected patients in the two communities in OR Tambo municipality of Eastern Cape, South Africa. The mental wellbeing and quality of life for people living with HIV and AIDS (PLWHA) is very important. These indices are known to delayed HIV disease progression and prolonged survival, especially in low income countries and in sub-Saharan Africa ${ }^{26}$. Therefore, an increase in access to highly effective antiretroviral therapy (ART) for PLWHA actually achieve these goals. The mental wellbeing of people living with HIV on one hand appears to require an added attention to the provision of ART for ensuring prolonged survival. Depressed persons with HIV frequently become non-adherent with their treatment, which may lead to higher HIV viral loads, higher infectiousness and poorer clinical outcomes ${ }^{15}$. Studies have also shown that depressive symptoms have been associated with risky behavior, non-adherence to medications and shortened survival ${ }^{16}$, and a rapid progression of HIV to AIDS with an increase in mortality among PLWHA ${ }^{27}$. This explains the rationale of this study, since the objectivity to accentuate factors responsible for depression are paramount. Failure to recognize these factors and arrest them would render both the patient and the larger community in danger (Urison, 2014).

\section{Limitations of the study}

The study only considered prevalence of depression in people living with HIV and AIDS, while other concepts surrounding depression and stressors such as strain, conflict, burnout and pressure were not addressed. The instrument utilized for collecting data was standardized and did not allow for in depth interview with the research participants. Also the instrument utilized was a self-report instrument, which is subject to response bias. The sample was taken from two Health Care Centers in O.R. Tambo and as such the study cannot be generalized to the whole population of O.R. Tambo District.

\section{Recommendations}

A similar study on a larger scale should be conducted that will include more males and members of other race groups aside from the predominant blacks. This should focus on how adults manage the depressive symptoms, with the recommendation that provides diverse result of demographic factors and depression; and for the strengthening of protective factors and reducing risk factors.

Due to the pervasive nature of depression and its consequences in people accessing ART further research on perceived social support and stigma is thus vital which will further explore these issues.

\section{Conclusion}

The prevalence of depressive symptoms is high (44\%) in HIV patients and depressive symptoms are associated with demographic factors more than non-adherence to HAART. This implies that depressed HIV-positive patients faced more demographic challenges than the tendency of not to follow up their treatment. This however, increases the possibility of complications and poor prognosis. Gender and unemployment were found to be factors significantly associated with occurrence of depressive symptoms in HIV-positive patients. Therefore, establishment of guidelines for routine screening of mental health of HIV-positive patients with depressive symptoms will improve both compliance with HAART and the outcome of the treatment of the disease. 


\section{Abbreviations}

AIDS-Acquired Immune Deficiency Syndrome

ART-Antiretroviral therapy

ARV-Antiretroviral

BDI-11- Beck's Depression Inventory revised tool

CHC-Community Health Care

Cl-Confidence Interval

HAART- Highly active antiretroviral therapy

HIV-Human Immunodeficiency Virus

HIV/AIDS-Human Immunodeficiency Virus/Acquired Immune Deficiency Syndrome

IL-Illinois

PLWHA-People Living with HIV and AIDS

PLWHIV-People Living With HIV

PSJ-Port Saint Johns

MCHC-Makhotyana Community Health Care

OR TAMBO-Oliver Reginald Tambo

SPSS-Statistical Package for Social Sciences

UNAIDS- Joint United Nations Programme on HIV and AIDS

USA-United States of America

WHO-World Health Organization

XBDI-11-isiXhosa version of Beck's Depression Inventory revised tool

\section{Declarations}

\section{Ethics approval and consent to participate}

The study was approved by the Ethical Committee of Walter Sisulu University on Human Subjects (protocol number 050/2017). Permission from the Eastern Cape Department of Health was granted to conduct the research in the two Community Health Centers. Participants' consent was sought and approved before enrolment of each participant.

Consent for publication: Not applicable

\section{Availability of data and materials}

The datasets generated and analyzed during the current study are not publicly available, but are available from the corresponding author on reasonable request. 
Competing interests: The authors declare that they have no competing interests.

\section{Funding}

All funds used in the design of the study and collection, analysis, and interpretation of data and in writing the manuscript were borne by respective authors. No external funding body involved.

\section{Authors' contributions}

YZD co-developed the study concept and collected data on human subjects

TA did statistical analysis of the results for this publication

DTA co-developed study concept, supervised the research study and wrote the manuscript

All authors have read and approved the manuscript.

\section{Acknowledgements}

Prof. Daniel Ter Goon-for proof reading of the manuscripts with useful suggestions

Authors' information

\section{Dlulane, Yola Zimasa (Female)}

Master degree student (Master of Public Health) in the Department of Public Health, Faculty of Health Sciences. Walter Sisulu University, Mthatha, Eastern Cape-South Africa

\section{Apalata Teke (Male)}

MD, MMed, PhD. Medical Microbiology consultant, Senior Lecturer and Head: Department of Laboratory Medicine and Pathology. Faculty of Health Sciences. Walter Sisulu University, Mthatha, Eastern Cape-South Africa

\section{Abaver Dominic Targema (Male)}

B.Sc., M.Sc., PhD. Senior Lecturer. Division of Medical Microbiology, Department of Laboratory Medicine and Pathology, Faculty of Health Sciences. Walter Sisulu University, Mthatha, Eastern Cape-South Africa

\section{References}

1. UN Joint Programme on HIV/AIDS (UNAIDS). Global HIV \& AIDS Statistics 2019 Fact sheet. https://www.unaids.org/en/resources/fact-sheet Accessed 23 April 2020

2. Statistics South Africa. Mid-year population estimates 2019. https://www.statssa.gov.za/publications/P0302/P03022019.pdf Accessed 23 April 2020.

3. Human Sciences Research Council (HSRC). The Fifth South African National HIV Prevalence, Incidence, Behaviour and Communication Survey 2017: HIV Impact Assessment Summary Report. http://www.hsrc.ac.za/uploads/pagecontent/9234/sabssmv_impact_assessment_summary_za_ads_cleared_pdfa4.pdf. Accessed 23 April 2020

4. UN Joint Programme on HIV/AIDS (UNAIDS). People living with HIV receiving ART as at June 2019. https://aidsinfo.unaids.org/ Accessed 20 February 2020

5. Van Damme W, Kober K, Kegels G. Scaling-up antiretroviral treatment in Southern African countries with human resource shortage: How will health systems adapt? Social Science and Medicine. 2008; 66(10): 2108-2121. 
6. South African National Aids Council (SANAC). South Africa's National Strategic Plan for HIV, TB and STIs 2017-2022. https://sanac.org.za/the-national-strategic-plan/ Accessed 23 April 2020

7. Alan JG, Heather SH. Assessing and Treating Depression in Primary Care Medicine. The American Journal of Medicine. 2006; 120(2):105-108

8. World Health Organization. HIV and mental health, WHO Press, Geneva. https://www.who.int/hiv/pub/imai/om.pdf? ua=1 Accessed 24 May 2020

9. Freeman M, Patel V, Collins PY, Bertoloite J. Integrating mental health in global initiative for HIV/AIDS. British Journal of Psychiatry. 2005; 187:1-3

10. World Health Organisation. Adherence to long term therapies: policy for action; WHO Press, Geneva. https://apps.who.int/iris/handle/10665/66984 Accessed 24 May 2020

11. Petrushkin A, Boardman J, Ovuga E. Psychiatric disorders in HIV- positive individuals in urban Uganda. Psychiatric Bulletin. 2005; 29:55-458.

12. Cruess DG, Evans DG, Repetto MJ, et.al. Prevalence, diagnosis, and pharmacological treatment of mood disorders in HIV disease. Biol Psychiatry. 2003; 54:307-16.

13. Bhagwanjee A, Parekh A, Paruk Z, Petersen I, Subedar H. Prevalence of minor psychiatric disorders in adult African rural community in South Africa. Psychol Med. 1998; 28(5):1137-1147.

14. Moosa MYH, Jeenah FY. Treating depression in HIV positive patients affects adherence. Southern African Journal of HIV Medicine. 2012; 13(3):

15. Do AN, Rosenberg ES, Sullivan PS, Beer L, Strine TW, Schulden JD, Fagan JL, Freedman MS, Skarbinski J. Excess burden of depression among HIV infected persons receiving medical care in the United States: data from the medical monitoring project and the behavioral risk factor surveillance system; PlosOne. 2014; 24:9(3).

16. Hemalatha N, Savarimuthu A. A study on Depression among HIV persons. Journal of Business Management \& Social Sciences Research. 2014; 3(7):243-251

17. Urison, A: HIV and Depression. https://www.health24.com/Medical/HIV-AIDS/Living-with-HIV/HIV-and-Depression$\underline{20130605}$ Accessed July 2019.

18. Edwards DJA, Steele GI. Development and validation of the Xhosa translations of the Beck Inventories: 3 Concurrent, convergent and discriminant validity. Journal of Psychology in Africa. 2008; 18(2): 227-236

19. Bowling A. Measuring Health: a review of quality of life measurement scales; Open University Press. England: Education; 2005. 211

20. Bhatia MS, Munjal S. Prevalence of Depression in People Living with HIV/AIDS undergoing ART and Factors Associated with it. Journal of Clinical and Diagnostic Research.2014; 8:10

21. World Health Organisation. Promoting mental health: Concepts, emerging evidence, practice. WHO Press, Geneva. https://www.who.int/mental_health/evidence/en/promoting_mhh.pdf Accessed 24 May 2020

22. Nogueira Campos L, De Fatima Bonolo P, Crosland Gulmaraes MD. 2006; Anxiety and depression assessment prior to initiating antiretroviral treatment in Brazil. AIDS Care. 2006; 18(6):529-536

23. Nolen-Hoeksema S, Larson J, Grayson C; 1999; Explaining the gender difference in depressive symptoms; JPers Soc Psychol 77(5): 1061-12 PMID:10573880

24. UN Joint programme on HIV/AIDS (UNAIDS). HIV - Related Stigma, Discrimination and Human Rights Violations. http://data.unaids.org/publications/irc-pub06/jc999-humrightsviol_en.pdf. Accessed 22 May 2020

25. Simbayi LC, Kalichman S, Strebel A, Cloete A, Henda N, Mqeketho A. Internalized stigma, discrimination, and depression among men and women living with HIV/AIDS in Cape Town South Africa. Social Science and Medicine. 2007; 64:18231831.

26. Douaihy A, Singh N. Patient care: factors affecting quality of life in patients with HIV infection. In: John WC, Editor. Quality Inquiry and Research Design. Los Angeles/London/New Delhi/ Singapore/Washington DC: Academic; 450-475. 
27. Glaser R, Kiescolt-Glaser JK. Stress-induced immune dysfunction: implications for health. Nature reviews immunology. 2005; 5: 243-251

\section{Figures}

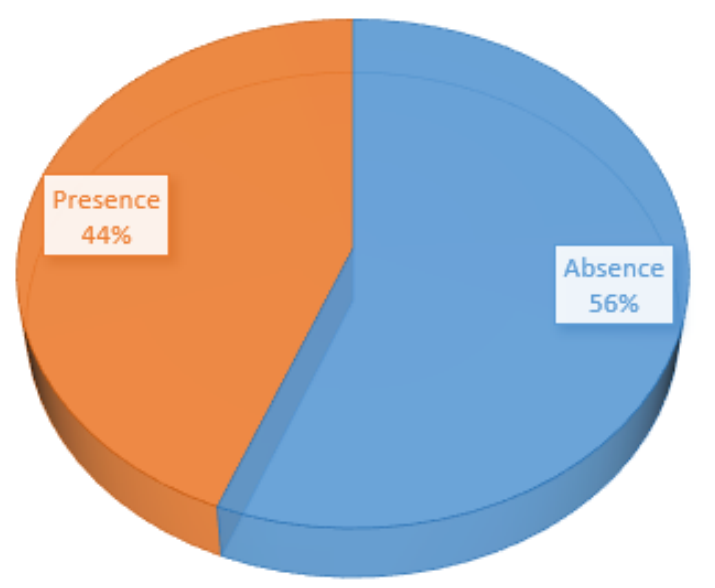

\section{Figure 1}

Prevalence of depression among HIV patients on ART

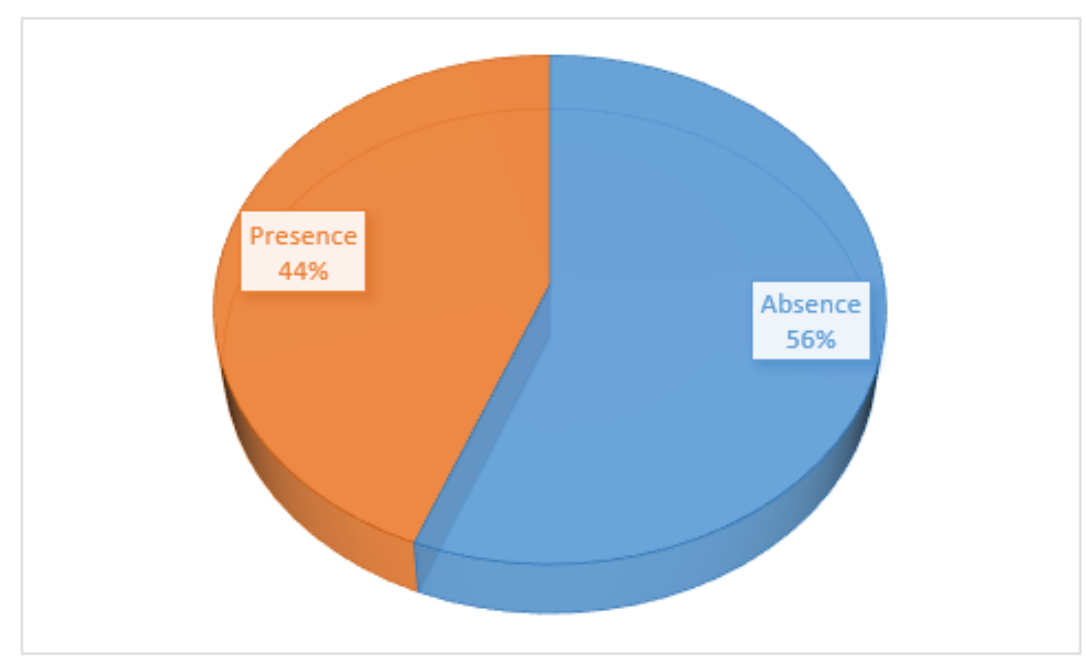

\section{Figure 1}

Prevalence of depression among HIV patients on ART 


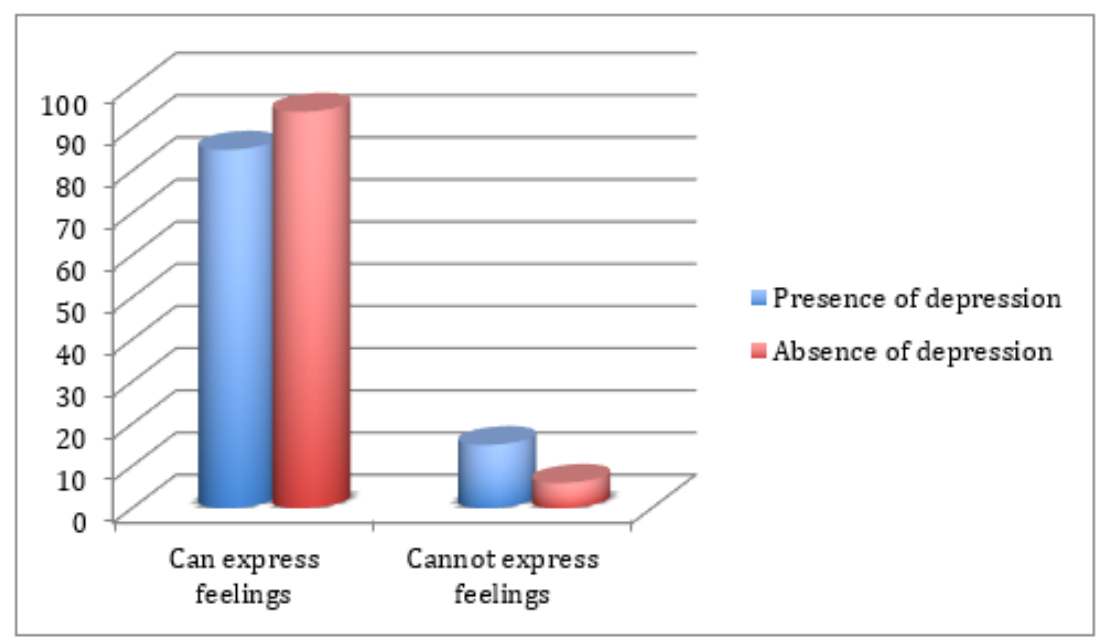

\section{Figure 2}

Ability to express feelings of HIV disease and challenges in accessing ART

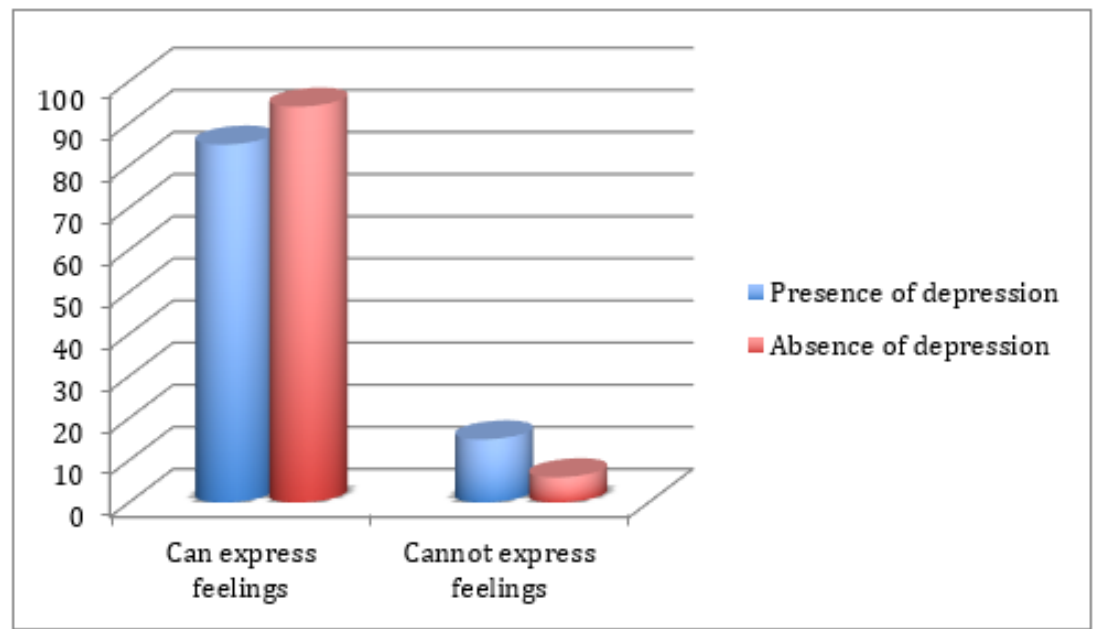

\section{Figure 2}

Ability to express feelings of HIV disease and challenges in accessing ART

\section{Supplementary Files}

This is a list of supplementary files associated with this preprint. Click to download.

- STROBEchecklist.docx

- STROBEchecklist.docx 